\title{
Social Exclusion and the Deconstructed State: Time Perception, Meaninglessness, Lethargy, Lack of Emotion, and Self-Awareness
}

\author{
Jean M. Twenge \\ San Diego State University
}

\author{
Kathleen R. Catanese and Roy F. Baumeister \\ Case Western Reserve University
}

\begin{abstract}
The authors hypothesize that socially excluded individuals enter a defensive state of cognitive deconstruction that avoids meaningful thought, emotion, and self-awareness, and is characterized by lethargy and altered time flow. Social rejection led to an overestimation of time intervals, a focus on the present rather than the future, and a failure to delay gratification (Experiment 1). Rejected participants were more likely to agree that "Life is meaningless" (Experiment 2). Excluded participants wrote fewer words and displayed slower reaction times (Experiments 3 and 4). They chose fewer emotion words in an implicit emotion task (Experiment 5), replicating the lack of emotion on explicit measures (Experiments 1-3 and 6). Excluded participants also tried to escape from self-awareness by facing away from a mirror (Experiment 6).
\end{abstract}

The desire to be accepted by other people is one of the most basic and pervasive human drives (Baumeister \& Leary, 1995). When that drive is thwarted through social exclusion or rejection, people react in a variety of negative ways. People who have been ostracized report decrements in physical health and increases in stress and anxiety (K. D. Williams, 2001). People who feel excluded or rejected often become more aggressive as a result (Kirkpatrick, Waugh, Valencia, \& Webster, 2002; Leary, Kowalski, Smith, \& Phillips, 2003; Twenge, Baumeister, Tice, \& Stucke, 2001). Self-defeating behavior often increases among socially excluded people (Twenge, Catanese, \& Baumeister, 2002), and rejected people experience declines in self-esteem (Leary, Tambor, Terdal, \& Downs, 1995). Prisoners who have been subjected to solitary confinement show an increase in psychotic behaviors (McGuire \& Raleigh, 1986).

Why does social exclusion cause these negative outcomes? Early theorizing proposed that heightened states of emotional distress would mediate between social exclusion and negative behavior. Although intuitively plausible, the emotional distress theory has not received much support. We have found that social exclusion produces few differences in emotion but large differences in behavior (Baumeister, Twenge, \& Nuss, in press; Twenge

Jean M. Twenge, Department of Psychology, San Diego State University; Kathleen R. Catanese and Roy F. Baumeister, Department of Psychology, Case Western Reserve University.

Roy F. Baumeister is now at the Department of Psychology, Florida State University.

During part of the completion of this research, Jean M. Twenge was supported by National Institute of Mental Health National Research Service Award Postdoctoral Grant MH12329. We thank Janet Cacho, Dina Cuervo, and Jay Rudeen for serving as experimenters and Sander Koole for his invaluable help with the computer program in Experiment 5.

Correspondence concerning this article should be addressed to Jean M. Twenge, Department of Psychology, San Diego State University, 5500 Campanile Drive, San Diego, California 92182-4611. E-mail: jtwenge@mail.sdsu.edu et al., 2001, 2002; however, Buckley, Winkel, \& Leary, 2002, and K. D. Williams, Cheung, \& Choi, 2000, did find significant effects for mood using somewhat different manipulations). Even when the effects on emotion do reach significance in our research, they have failed to mediate the relationship between exclusion and negative behaviors. Even K. D. Williams (2001), who has found some significant effects of ostracism on anxiety and other mood reports, observed that victims of ostracism often seem to respond in a numb and neutral manner rather than with overt displays of emotion: "It was as though they had been hit with a stun gun" (p. 159).

In this article, we hypothesize that social exclusion will lead to feelings of inner numbness. People may respond with empty, neutral, and even bored feelings when their need to belong is thwarted, rather than the acute emotional distress that at first seemed plausible. In fact, such numbness could ward off the emotional distress that might otherwise arise by defensively isolating affect and keeping negative feelings out of awareness (e.g., Massong, Dickson, Ritzler, \& Layne, 1982). This state has been characterized as one of cognitive deconstruction, which is marked not only by a lack of emotion but also by an altered sense of time, an immersion in the present rather than past or future, a relative absence of meaningful thought, and lethargy, all of which may be driven by the attempt to escape from aversive self-awareness (Baumeister, 1990, 1991; see also Vallacher \& Wegner, 1985, 1987). In other words, people may use the deconstructed state as a defense against the negative experience of social rejection.

\section{Suicide, Exclusion, and Deconstruction}

To construct a theoretical approach, we consulted another literature-research on suicide-in which emotional distress was intuitively plausible, but findings failed to confirm hypotheses. It seemed logical to assume that people who kill themselves (or even attempt to do so) must be suffering from acute unhappiness. Contrary to that view, most findings suggest that the presuicidal state is marked by flat affect. For example, suicidal people find it more difficult to recall emotion-laden memories (J. M. Williams \& 
Broadbent, 1986) and perform better on tasks with affectively neutral stimuli (Geller \& Atkins, 1978).

Building on those observations, Baumeister (1990) proposed that the presuicidal state is characterized by a defensive reaction called cognitive deconstruction. Most suicide attempts are preceded by some failure or setback that reflects badly on the self. The person seeks to avoid the aversive self-awareness and the acute emotional distress that would ensue from thinking about the implications of this recent failure. This is accomplished by having a narrowly concrete focus on the immediate present rather than a broadly meaningful thought pattern. Vallacher and Wegner (1985) described this state as low levels of action identification. This here-and-now focus may be successful in warding off the intense emotion that would accompany meaningful self-awareness, but it causes other undesirable effects. Inhibitions are undermined because most of them involve meaningful prescriptions about behavior, and so the deconstructed state can cause a variety of impulsive and disinhibited behavior (of which suicide attempts are one important form). Without meaning, time seems to drag, and the person remains stuck in a relatively empty present moment, cut off from past and future. Deprived of reasons for action, the person may become passive, lethargic, and idle (which may at least reduce the number of actual suicide attempts).

Several parallels between suicide research and the impact of social exclusion suggested that the deconstructed state might be relevant to both. First, being rejected or excluded from social groups is often a negative experience that could reflect badly on the self, which is just the sort of experience that typically precedes suicide attempts. Excluded people may therefore be wishing to avoid self-awareness and the accompanying thoughts about what might be wrong with them (to have caused others to reject them). Second, as already noted, the absence of emotion was a surprising but repeated finding in both literatures.

Third, there have been some signs of lethargy among rejected or ostracized individuals. K. D. Williams's (2001, chapter 7) allusion to the "stun gun" effect of being ostracized was an attempt to integrate a pattern of observations on how research participants looked and acted after the people sitting on either side of them had studiously ignored them while talking to each other. They slumped, stared at their feet, showed no emotion, ignored everything around them, and even sat there doing nothing when the experiment was ended and everyone else got up to leave. In other research, K. D. Williams, Cheung, and Choi (2000) reported an increase in conformity among people who had been ostracized. The authors interpreted this as a bid to win acceptance by acting like other people, but it could also reflect passivity: The person conforms rather than acting in an independent, self-assertive manner.

Fourth, just as suicide is self-destructive, self-destructive behavior has been found to follow from social exclusion. Laboratory studies by Twenge et al. (2002) found increases in an assortment of self-defeating behaviors among participants who had been socially excluded: They made a higher proportion of unhealthy choices, procrastinated, and took foolish risks. Some of these patterns also reflect the impulsive aspect of the deconstructed state.

Last, there is a direct link between social exclusion and suicide, which has been apparent for over a century. Durkheim (1897/ 1963) showed that suicide rates are highest among people who are not well integrated into society as a whole, and subsequent work has continued to support this conclusion (e.g., Trout, 1980). Many suicide attempts are directly traceable to recent experiences of social exclusion, such as loss of job or marriage, and suicide rates are elevated in ethnic groups or occupational categories dwindling in size (see Baumeister, 1990, for review).

On the basis of these parallels, we hypothesized that social exclusion might well produce the deconstructed state identified in presuicidal individuals. If social exclusion thwarts a basic human drive and challenges one's self-worth, then people might prefer to escape self-awareness and emotional distress by hiding out in a mental state marked by numbness, lack of meaningful thought, and a narrow focus on concrete, immediate stimuli. We hypothesize that both social rejection (being rejected by a group of peers) and social exclusion (hearing that one will be alone later in life) will lead to the deconstructed state. These are somewhat different experiences; rejection is more unambiguously personal, but may be confined to a specific incident, whereas exclusion is less personal but longer lasting. Although these two experiences may differ, we hypothesize that their behavioral and emotional effects will be similar.

\section{Predictions: Exclusion and Deconstruction}

The present investigation used a series of experiments that manipulated social exclusion and then measured various features of the deconstructed state. It would be excessive to propose that a simple laboratory manipulation of social exclusion compares with a presuicidal state. However, these manipulations might make self-awareness aversive enough for people to seek refuge in emotional numbness and an absence of meaningful thought. Our predictions were therefore as follows.

\section{Present Orientation Versus Future Orientation}

One of the main components of the deconstructed state of suicidal patients is a focus on the present instead of the future. Suicidal people find it difficult to think about the future (Neuringer \& Harris, 1974), and they cannot make elaborate predictions about the future (Yufit \& Benzies, 1973). When given a sentencecompletion task, these patients choose fewer future-tense verbs, as compared with control participants (Greaves, 1971). Many seem unable to envision the future and even unable to name any potential consequences of killing themselves (Weiss, 1957). They focus on the present and do not wish to deal with the future.

Time span is correlated with meaning. As Vallacher and Wegner $(1985,1987)$ showed, meaningful thought at high levels of action identification encompasses long time spans, extending into the past and future, whereas less meaningful forms of thought focus on narrow slices of time, especially the immediate present. If social exclusion causes a shift toward the deconstructed state, then excluded participants should be more focused on the present rather than the future.

\section{Disordered Time Perception}

According to some theories, this focus on the present represents some people's defensive attempts to stop time and not think about a hopeless future (Hendin, 1982). This leads to a distorted time perception in which the present seems to last longer than usual. 
When asked to estimate how much time had elapsed during 30-s and 60-s intervals, suicidal patients overestimated the amount of time that had passed (Neuringer \& Harris, 1974). In contrast, control participants estimated the time intervals fairly accurately. Several other studies found similar results (e.g., Blewett, 1992; Brockopp \& Lester, 1970; Greaves, 1971; Tysk, 1984; Wyrick \& Wyrick, 1977).

Time perception can be distorted in either direction, of course. Under some circumstances, people may underestimate time intervals. The "flow" state identified by Csikszentmihalyi (1990) is typically described as a loss of the sense of the passage of time, so that people in flow are often surprised to discover how late it has grown while they were immersed in their activities. Flow is the opposite of deconstructed numbness, even though both can be described as some kind of immersion in the present. In flow, awareness is absorbed in some deeply satisfying activity, and so each moment is rich. In deconstruction, the present serves as an escape from meaningful activity, and so it is experienced as relatively empty, even oppressively boring. The two states have opposite effects: Someone in flow finds that time flies, whereas someone in a deconstructed state finds that time drags.

Hence, we predicted that social exclusion should distort the perception of time flow in the same way that deconstruction does. That is, excluded individuals should overestimate the duration of experimentally controlled intervals. In that way, they would resemble severely bored people for whom time drags by slowly. The opposite distortion, in which they would underestimate the duration of intervals, is more characteristic of meaningful absorption in stimulating activity, and that seemed very unlikely among socially excluded individuals.

\section{Meaninglessness}

The deconstructed state also includes a tendency to reject meaning and higher order explanations. Suicidal people are cognitively rigid and use a narrow perspective as a way to cope with their situation (Baumeister, 1990). In addition, they see little meaning in life and believe that life is not worth living. One study found a connection between suicidal tendencies and lack of perceived meaning in life (Edwards \& Holden, 2001). Rogers (2001) has asserted that a failure to create meaning underlies most suicide attempts. Social exclusion may produce a similar mental state, as a present or future without close relationships may seem meaningless. K. D. Williams (2001) theorized that ostracism threatens meaningful existence because being ignored by others simulates the invisibility and worthlessness of death (pp. 63-64). Across several studies, K. D. Williams and his colleagues found that ostracized people reported that their sense of meaningful existence had been threatened (K. D. Williams, Bernieri, Faulkner, Grahe, \& Gada-Jain, 2000; K. D. Williams et al., 2002; K. D. Williams, Shore, \& Grahe, 1998).

Meaningful thought is an important basis for self-awareness and emotion, as these depend on interpreting one's current situation and comparing it with standards. Rejection may threaten meaningfulness because it strikes a blow against one's anticipated future life as surrounded with friends and family. At a simpler level, meaningful thought may be aversive in the wake of rejection because the person is tempted to ask why he or she was rejected, and many possible answers would reflect badly on the self. Evad- ing meaningful thought is therefore important for the strategy of warding off aversive self-awareness and emotional distress.

In the present investigation, we included a brief measure of perceived meaningfulness of life, and we predicted that social exclusion-even a laboratory manipulation that was separate from all the meaningful aspects of the person's life outside the laboratory-would cause participants to shift toward perceiving less meaning in their lives.

\section{Lethargy}

Suicidal people often display chronic passivity and lethargy, which constitute another characteristic of the deconstructed state. Suicide notes often express acceptance and passive submission (Henken, 1976), and suicidal patients are generally more passive (Gerber, Nehemkis, Farberow, \& Williams, 1981; Mehrabian \& Weinstein, 1985). These patients also exhibit an external locus of control and thus perceive personal action as unnecessary, because they feel their fate is out of their hands (Gerber et al., 1981; Melges \& Weisz, 1971; Topol \& Reznikoff, 1982). As Baumeister (1990) observed, passivity further enables those in the deconstructed state to escape from self-awareness.

In addition, passivity and lethargy may result from the deconstructed state because many actions and decisions require meaningful thought, which is aversive in the wake of rejection. That is, a rejected person may minimize emotional distress by avoiding meaning, but the basis for intelligent and planful action is undermined as well. (Impulsive or aimless activity, automatic responses, and simple compliance with clear external demands would not be prevented, however, because these do not require meaningful choice.) Moreover, self-conscious action tends to implicate the self as a responsible agent, so people who wish to avoid self-awareness may shun such action. As noted above, social ostracism leads to lethargic behavior (K. D. Williams, 2001), although up to now those reports have been anecdotal. In the present investigation, we measured lethargy during a writing task and a reaction-time task.

\section{Lack of Emotion}

Presuicidal individuals tend to report an absence of emotion (e.g., Geller \& Atkins, 1978; J. M. Williams \& Broadbent, 1986), which at first seems counterintuitive. After all, if one is not upset, why try to kill oneself? Baumeister (1990) proposed that the presuicidal state is actually accompanied by defensive efforts to shut down one's emotional responses to avoid the acute distress that might accompany meaningful thought about one's circumstances, which for presuicidal people are often quite negative.

As already indicated, the lack of emotion observed in our previous studies of social exclusion (e.g., Baumeister et al., 2002; Twenge et al., 2001, 2002) came as a surprise and prompted us to revise our assumptions about what mediates the behavioral effects of thwarting the need to belong. We were reluctant to conclude that the lack of emotion meant that participants were fully indifferent to the manipulations of social rejection and exclusion. Instead, we began to think that they entered into the deconstructed state as a way of warding off emotion and defending themselves against negative affect.

A simpler explanation for the lack of self-reported emotion in our studies is that participants have simply been reluctant to admit 
to feeling upset. Possibly they thought they would lose face if they acknowledged how upset they were after being rejected by others. The present investigation included some self-report measures of emotion, but we also included implicit measures of emotional response. If the lack of emotion is merely an artifact of self-report bias and impression management concerns, then participants might show heightened emotionality on implicit measures. In contrast, if they really have entered into a numb state as a defensive way of shutting down their emotions, then they should show little or no emotion on the implicit measures and might even avoid emotional responses.

\section{Escape From Self-Awareness}

The deconstructed state includes escape from emotional distress, but the emotional distress itself stems from self-awareness in connection with recent failures or setbacks (Baumeister, 1990, 1991). In fact, suicide attempts may occur because the person cannot escape from self-awareness by other means, so death becomes desirable as a form of oblivion (Baumeister, 1990). Consistent with that view, presuicidal individuals seem to struggle with aversive self-awareness. Suicide notes contain a greater percentage of first-person singular pronouns (and not of first-person plural pronouns, which would imply interpersonal connection) compared with other documents, simulated suicide notes, and even notes written by people who are facing involuntary death (Henken, 1976). Use of first-person pronouns is a well-established measure of self-awareness (e.g., Wegner \& Giulano, 1980). Thus, suicidal people seem to experience a high level of self-awareness, perhaps so high that they seek escape through death.

Therefore, our final prediction was that social exclusion would lead to avoiding self-awareness. Being rejected or otherwise excluded would focus attention on the individual self as not part of the group and possibly as having socially undesirable traits. Because most people desire to gain social acceptance and maintain satisfying relationships with others, an experience of social exclusion could signify that something is wrong with the self. Contemplating one's possible shortcomings would presumably be an aversive exercise in self-awareness. Hence, excluded people should want to defensively avoid self-awareness.

\section{Experiment 1}

Experiment 1 provided a direct test of the effect of social rejection on time perception, delay of gratification, and emotion. The deconstructed state includes a relative lack of emotion and a perception that time is dragging. Thus we predicted that rejected people would report relatively little emotion and would exhibit several departures from a normal time orientation. Specifically, they would overestimate the duration of time intervals and would exhibit a present rather than a future time focus. The present orientation should also work against delay of gratification, as delay of gratification requires the person to forgo immediate rewards for the sake of a better future.

In our procedure, groups of participants first engaged in a structured conversation designed to help them get to know each other. After this, all participants were asked to name the two people with whom they would most like to work in pairs. By random assignment, half the participants were told that no one had expressed an interest in working with them, which constituted a palpable and seemingly unanimous social rejection; the other half heard that everyone chose them.

Participants then completed a battery of measures. First, they were asked to judge the length of two time intervals. The experimenter told participants that the stopwatch would run for a certain length of time, and they should give their best judgment of how much time had passed. If rejected participants show symptoms of the deconstructed state, they should perceive time as dragging and will think more time has passed than actually has. (In contrast, anything resembling the subjective "flow" experience would be reflected in underestimation of time intervals, signifying that time passes very rapidly.) Participants also completed a long mood measure (to test for flattened affect) and a future time orientation scale. Last, they were given a measure of delay of gratification, in the form of a hypothetical choice between two jobs that differed in short-term and long-term rewards.

\section{Method}

\section{Participants}

The participants were 54 undergraduates ( 33 men, 21 women) participating as part of a course requirement for introductory psychology. They were $76 \%$ White and $24 \%$ racial minority, and their average age was 18.8 years.

\section{Materials and Procedure}

Acceptance/rejection manipulation. Participants arrived at the lab in single-sex groups of 4-6 people. They were given nametags on which they wrote their first names. They were given both written and oral instructions to learn each other's names and then talk for about 15 min using a set of questions as a guide (the questions were taken from the Relationship Closeness Induction Task developed by Sedikides, Campbell, Reeder, \& Elliot, 1999). After $15 \mathrm{~min}$, the experimenter led the participants to separate rooms, where participants nominated the two group members they wanted to interact with again: "We are interested in forming groups in which the members like and respect each other. Below, please name the two people (out of those you met today) you would most like to work with." Instead of using these nominations, however, participants were randomly assigned to be accepted or rejected by the group. Accepted participants were told that everyone had picked them, and rejected participants heard that no one picked them. In both cases, they were told that they would work alone because of the unusual outcome. This procedure was adapted from Leary et al. (1995) and was used in Twenge et al. (2001).

Judgment of time intervals. Participants then judged the length of two time intervals. The experimenter said, "I'm going to let the stopwatch go for a certain amount of time, and when I stop it, I want you to tell me how much time passed." They were asked not to count or use their fingers to keep track of the time. The first time interval was $40 \mathrm{~s}$, and the participants estimated the amount of time that had passed. The second interval was $80 \mathrm{~s}$ The experimenter recorded each participant's estimates and did not give any feedback about the estimates. Because of experimenter error, some participants did not complete the time interval judgments, leaving a sample of 39 participants for the first time interval and 33 participants for the second time interval.

Emotion measures. All participants then completed a battery of questionnaires, beginning with a one-item mood measure ranging from 1 (negative) to 7 (positive). The next page asked the participant to rate his or her current mood on 41 adjectives using 7-point Likert scales. These included 8 adjectives describing positive affect (e.g., happy, calm) and 33 describing negative affect (e.g., angry, nervous, fearful, ashamed). 
Delay of gratification. Participants then completed a form describing the following scenario (modified from Kuhlen \& Monge, 1968):

A friend of yours of your own age has had two jobs offered to him/her. One job has a relatively high starting salary, but little promise of advancement or better income. The other job offers a starting salary that is considerably lower but with the possibility of substantial advancement and a much higher later income. Which job would you advise him/her to accept?

The two possibilities offered were: "A. the job with the higher immediate salary or B. the job starting with the lower salary, but with the possibility of much higher later income." Participants then responded to the question "How certain are you that this is what you would advise?" on a 7-point Likert scale ranging from 1 (not at all certain) to 7 (very certain). This was converted into a continuous scale ranging from 1 (very certain of nondelay response) to 14 (very certain of delay of gratification response). This served as a measure of delay of gratification; choice A favors a short-term gain at the expense of long-term gain, whereas choice B favors long-term gain over short-term gain. Choice B is thus scored as higher delay of gratification.

Time orientation self-report. Participants also responded to two selfreport measures of time orientation. The first was 10 items measuring present versus future time orientation using a 7-point Likert scale. The items were adapted from Kuhlen and Monge (1968) and Gjesme (1979), including items such as "I can only think about the present," "I find it difficult to think about the future," "I am most concerned about how I feel in the present," and "I feel a strong tendency to enjoy myself today and let the future take care of itself." This scale had an alpha reliability of .73 in this sample. This measure was scored in the direction of high scores indicating a future orientation, and low scores indicating a more present orientation. The second time orientation measure consisted of 20 items taken from the Zimbardo Time Perception Inventory (ZTPI; Zimbardo \& Boyd, 1999), which was originally developed as a trait measure. The items used here were reworded to serve as a state measure of time perception. For example, many items were changed to the present tense. These items yielded subscales based on the original ZTPI, including future orientation, past negative, past positive, hedonistic, and present fatalistic.

\section{Results and Discussion}

Would people rejected by their peers show distorted time perception, less orientation toward the future, less ability to delay gratification, and flattened affect? As Table 1 shows, all of these predictions were confirmed.

\section{Disordered Time Perception}

We predicted that rejected participants would experience a specific pattern of distortions in time perception, including a sense that time was moving slowly. When asked to judge a $40-$ s time interval, rejected participants estimated that more than a minute had passed $(M=63.71)$, whereas accepted participants were fairly accurate in their estimate $(M=42.50), F(1,37)=8.58, p<.006$. The results were similar for the 80 -s interval, with rejected participants again significantly overestimating the amount of time that had passed $(M=100.06)$, whereas accepted participants were more accurate $(M=71.13), F(1,31)=7.40, p<.01$. These overestimations are consistent with the deconstructed state, in which time drags by slowly.

\section{Future Versus Present Orientation}

Rejected participants were also more present oriented and less future oriented on a self-report scale, $F(1,50)=4.37, p<.05$. They were more likely to agree that they only wanted to think about the present and found it difficult to think about the future. Present orientation is another important feature of the deconstructed state, particularly because present activities often draw meaning from the future (such as goals or anticipated fulfillments). To defensively avoid meaning, one severs the present from the future.

Social exclusion did not produce significant differences on any of the scales of the other time perception inventory, the ZTPI. This may have occurred because the ZTPI was written originally as a trait measure and not as a state measure. Alternatively, the deconstructed state may not affect the categories of time perception measured by the ZTPI.

\section{Delay of Gratification}

The social exclusion manipulation also elicited different responses on the measure of delay of gratification. Accepted participants overwhelmingly (94\%) reported that they would advise a friend to take the job that had a lower starting salary but more possibilities for advancement (vs. a job with a higher starting salary and little promise of advancement). Such an approach

Table 1

The Effect of Social Exclusion on Time Perception, Future Orientation, Delay of Gratification, and Mood, Experiment 1

\begin{tabular}{|c|c|c|c|c|c|c|}
\hline \multirow[b]{2}{*}{ Dependent variable } & \multicolumn{2}{|c|}{ Accepted } & \multicolumn{2}{|c|}{ Rejected } & \multirow[b]{2}{*}{$F$} & \multirow[b]{2}{*}{$d f$} \\
\hline & $M$ & $S D$ & $M$ & $S D$ & & \\
\hline 40-s time interval & 42.50 & 14.81 & 63.71 & 27.47 & $8.58 * *$ & 1,37 \\
\hline 80 -s time interval & 71.13 & 25.86 & 100.06 & 34.34 & $7.40 * *$ & 1,31 \\
\hline Future orientation scale & 50.84 & 9.26 & 45.30 & 9.17 & $4.37 *$ & 1,50 \\
\hline ZTPI (modified) & 53.58 & 5.58 & 54.34 & 7.15 & 0.16 & 1,50 \\
\hline Delay of gratification ( $\%$ choosing delay) & \multicolumn{2}{|c|}{$94 \%$} & \multicolumn{2}{|c|}{$73 \%$} & \multicolumn{2}{|c|}{$\chi^{2}(1, N=51)=4.74 *$} \\
\hline Delay of gratification confidence rating $(1-14)$ & 12.56 & 2.01 & 9.48 & 4.60 & $7.23 * *$ & 1,49 \\
\hline One-item mood rating (1-7) & 5.05 & 0.85 & 4.40 & 1.03 & $5.53 *$ & 1,52 \\
\hline Negative mood & 47.16 & 17.72 & 43.56 & 15.88 & 0.58 & 1,52 \\
\hline Positive mood & 28.37 & 10.30 & 28.89 & 9.94 & 0.03 & 1,52 \\
\hline
\end{tabular}

Note. $\quad$ ZTPI $=$ Zimbardo Time Perception Inventory.

$* p<.05$. ** $p<.01$. 
represents a willingness to delay gratification and an adaptive ability to integrate the present and the future. In contrast, rejected participants were significantly less likely to make this choice (73\%), $\chi^{2}(1, N=51)=4.74, p<.03$. Compared with accepted participants, significantly more rejected participants chose to take the immediate rewards despite the long-term costs. True, the majority of rejected participants recognized that delaying gratification was the best choice, but a significant minority favored short-term rewards over long-term benefits.

The certainty of their choice, calculated on a 14-point scale, was also significantly different between groups, $F(1,49)=7.23, p<$ .01 . Even when rejected participants chose the delay option, there was a trend toward less confidence in their choice ( $M$ for rejected $=11.92, M$ for accepted $=13.00$, only among participants who chose the delayed gratification option), $F(1,39)=3.08$, $p<.09$.

\section{Lack of Emotion}

Accepted and rejected participants differed significantly on the one-item mood measure but showed no significant differences on the detailed mood measure. On the one-item, 7-point holistic measure, rejected participants averaged 4.40 and accepted participants averaged 5.05, $F(1,52)=5.53, p<.03$. Thus the difference was significant but small. Meanwhile, the more detailed mood measure uncovered no mood differences at all, in either positive or negative affect (see Table 1). This was true even when the scales were broken down into more specific scales; there were no significant differences in sadness, fear, embarrassment, or anger. This is consistent with previous research in our labs, which showed no significant differences in the Positive and Negative Affect Scale (PANAS; Baumeister et al., 2002; Twenge et al., 2001) or the Brief Mood Introspection Scale (BMIS; Twenge et al., 2002). Leary and colleagues (e.g., Buckley et al., in press) have found mood effects after social rejection, but in their methods the participants do not meet their rejecters in person; this may make the experience less traumatic and thus not produce the defensive response of numbness. Thus, rejection produced a small difference on a holistic measure of mood and no differences on a comprehensive, detailed mood list. Being rejected unanimously by a group of peers apparently did not elicit very much emotional distress, which is surprising and counterintuitive unless one proposes that they entered into a state of numbness that may be attractive precisely because it prevents distress.

Given the lack of a main effect for mood (on the detailed measure), it is not surprising that mood did not mediate the effect of rejection on any of the dependent variables. Exclusion (acceptance vs. rejection condition) was still significantly correlated with all of the dependent variables when these analyses were controlled for the detailed scales of positive and negative mood- $r(35)=.45$, $p<.01$ for the 40 -s time interval; $r(29)=.47, p<.01$ for the 80 -s time interval; $r(47)=.28, p<.05$ for future orientation; and $r(46)=.36, p<.02$ for the delay of gratification certainty ratings.

\section{Experiment 2}

Experiment 2 had three goals. First, we sought to measure the effects of social rejection on feelings of meaninglessness. Although K. D. Williams (K. D. Williams, Bernieri, et al., 2000;
K. D. Williams et al., 1998, 2002) found that ostracism threatened meaningful existence, two of these studies were not experimental, and all manipulated ostracism (a somewhat different concept and experience). We sought to measure feelings of meaning in life after random assignment to an experience of social acceptance or rejection. After being accepted or rejected, participants indicated their agreement or disagreement with the statement "Life is meaningless." Cognitive deconstruction is essentially an avoidance or rejection of meaningful thought, so we predicted that social exclusion would lead to greater perceptions that life is meaningless.

Second, we wanted to replicate the lack of emotion results of Experiment 1 using a different measure of mood, as a way of reducing the possibility that the null results were an artifact of an insensitive measure. Experiment 2 used a more general measure of mood (modified from K. D. Williams, Cheung, \& Choi, 2000), with items such as "bad-good."

Third, Experiment 2 included a manipulation check, asking participants if they felt rejected or accepted. This enabled us to confirm the effectiveness of the group rejection manipulation. Neither Experiment 1 nor our previous studies using that method have confirmed that the group rejection condition actually makes people feel that they have been rejected.

\section{Method}

\section{Participants}

The participants were 96 undergraduates (52 men, 44 women) participating to fulfill a course requirement in introductory psychology. They were $67 \%$ White and $33 \%$ racial minority, and their average age was 19.1 years.

\section{Measures and Procedure}

Participants experienced the same social rejection manipulation as in Experiment 1, hearing either that everyone or no one chose them after a group interaction. After receiving the false feedback, they completed several questionnaires. The first was a mood measure and manipulation check. The three mood items were drawn from K. D. Williams, Cheung, and Choi (2000) and asked participants to rate their mood on a Likert scale from 1 to 9 with the anchors of bad-good, sad-happy, and tense-relaxed. They also completed a manipulation check item, "rejected-accepted." Participants then rated their agreement with two questions, again on a 9-point Likert scale: "How true is the statement: 'Life is meaningless'?" and "How true is the statement 'I am in control of my life'?" The anchors for the Likert scale were $1=$ not at all true and $9=$ very much true.

\section{Results and Discussion}

\section{Manipulation Check}

As Table 2 shows, the manipulation caused participants to feel more rejected: Those rejected by the group reported significantly greater feelings of rejection than those in the accepted condition, $F(1,94)=14.67, p<.001$. This finding confirms that the rejection manipulation was effective. This should also enhance confidence in the results of Experiment 1, as that study used the same manipulation.

\section{Meaning in Life}

As Table 2 shows, rejected participants were significantly more likely than accepted participants to agree with the statement that 
Table 2

The Effect of Social Exclusion on Feelings of Meaninglessness, Sense of Control, Mood, and Acceptance Versus Rejection, Experiment 2

\begin{tabular}{|c|c|c|c|c|c|}
\hline \multirow[b]{2}{*}{ Dependent variable } & \multicolumn{2}{|c|}{ Accepted } & \multicolumn{2}{|c|}{ Rejected } & \multirow[b]{2}{*}{$F(1,94)$} \\
\hline & $M$ & $S D$ & $M$ & $S D$ & \\
\hline Agree that "life is meaningless" & 1.35 & 0.70 & 2.44 & 2.20 & $10.56^{* *}$ \\
\hline Agree that "I am in control of my life" & 6.52 & 2.15 & 7.00 & 1.97 & 1.30 \\
\hline Three-item mood measure & 19.98 & 4.01 & 19.35 & 5.31 & 0.42 \\
\hline Manipulation check: Rejected (low) versus accepted (high) & 7.35 & 1.82 & 5.83 & 2.07 & $14.67 * * *$ \\
\hline
\end{tabular}

$* * p<.01 . \quad * * * p<.001$

"Life is meaningless," $F(1,94)=10.56, p<.002$. As the mean (2.44 out of 9.00) illustrates, however, it is more accurate to say that rejected participants did not disagree with the statement as strongly as accepted participants did. Seventy-nine percent of rejected participants indicated disagreement with the statement by circling a number below the midpoint of 5 , but $21 \%$ agreed with the statement (circling a 5 or higher). None $(0 \%)$ of the accepted participants agreed with the statement; they all circled numbers between 1 and 4 . Thus, socially rejected people found less meaning in life, as predicted by deconstruction theory and K. D. Williams's (2001) theory of ostracism and threats to meaningful existence. Such a response may be part of a larger shift toward a deconstructed state that avoids meaning to prevent oneself from recognizing the possible implications of the social rejection.

\section{Feelings of Control}

In contrast to the effect of rejection on meaningfulness, rejected participants did not report feeling a lack of control (see Table 2). This suggests that social rejection does not affect all attitudes about life, but (in this case) meaninglessness in particular.

\section{Lack of Emotion}

The results of this experiment also confirmed the lack of emotion displayed by the participants in Experiment 1. The accepted and rejected groups did not differ on the composite, three-item measure of mood (see Table 2). There were also no significant differences on the individual items. Thus, participants did not show increased negative mood or decreased positive mood as the result of social rejection. This is consistent with deconstruction theory, which predicts that socially rejected people will display flattened affect. The results should be interpreted with caution, however, as one cannot confirm a hypothesis with a null effect.

We also found that mood did not mediate the effects. The bivariate correlation between condition (acceptance vs. rejection) and feelings of meaninglessness was $r(94)=.32, p<.002$. When controlled for mood, it was essentially unchanged, $r(93)=.31$, $p<.002$. Mood was not correlated with feelings of meaninglessness in a bivariate analysis, $r(94)=.15, n s$, or when controlled for condition, $r(93)=.13, n s$.

\section{Experiment 3}

In Experiment 3, we measured the effect of social exclusion on lethargic passivity. One hallmark of the deconstructed state is that meaningful action is undermined by the avoidance of meaningful thought and also by a reluctance to accept responsibility onto the self.

Lethargy and passivity are notoriously difficult to measure, especially among laboratory participants who often arrive full of energy and eager to explore the experience or at least get it over with. We measured lethargy by asking participants to write definitions for 10 common proverbs in $10 \mathrm{~min}$. Such a task clearly requires meaningful thought, as the person must move from the stimulus sentence to the broader meaning and then reformulate that meaning in his or her own words. The lethargic response would be to write less and not to exert the energy necessary to give long, detailed definitions of the proverbs. The active response would be to generate a large number of words in the process of defining the proverbs. If excluded participants are feeling lethargic and numb as part of the deconstructed state, we would expect them to generate fewer words.

To strengthen generalizability, we used a different manipulation of social exclusion. Participants were given a personality inventory and heard false feedback about the results. In the crucial "future alone" condition, they were told that they were likely to end up alone later in life. The first control group heard that they would have good relationships throughout life (future belonging). In a second control condition, participants heard that they would be accident prone later in life, which is a negative outcome unrelated to social exclusion (future misfortune).

We measured both self-esteem and mood as possible mediators. We used yet another measure of mood, the PANAS (Watson, Clark, \& Tellegen, 1988) to test for mood differences among the conditions. In addition, we administered the State Self-Esteem Scale (SSES; Heatherton \& Polivy, 1991) to test for mediation by state self-esteem. Perhaps social exclusion leads to decreased self-esteem, which then leads to the depressive deconstructed state.

\section{Method}

\section{Participants}

The participants were 43 undergraduates ( 23 men, 20 women) participating as part of a course requirement for introductory psychology. They were $74 \%$ White and $26 \%$ racial minority, and their average age was 18.4 years.

\section{Materials and Procedure}

Participants were first asked to fill out a personality questionnaire (the Eysenck Personality Questionnaire [EPQ]; Eysenck \& Eysenck, 1975). 
Participants were randomly assigned to one of three social exclusion conditions: future alone, future belonging, or future misfortune. To gain credibility, the experimenter first gave an accurate assessment of the participant's extraversion score, providing correct feedback about whether the score was high, medium, or low on this scale. The experimenter used this as a segue into reading a randomly assigned "personality type" description. In the future alone condition, the participant was told the following:

You're the type who will end up alone later in life. You may have friends and relationships now, but by your mid-20s most of these will have drifted away. You may even marry or have several marriages, but these are likely to be short-lived and not continue into your 30s. Relationships don't last, and when you're past the age where people are constantly forming new relationships, the odds are you'll end up being alone more and more.

In contrast, people in the future belonging condition were told the following:

You're the type who has rewarding relationships throughout life. You're likely to have a long and stable marriage and have friendships that will last into your later years. The odds are that you'll always have friends and people who care about you.

Last, a future misfortune condition was included, in which people were told the following:

You're likely to be accident prone later in life-you might break an arm or a leg a few times, or maybe be injured in car accidents. Even if you haven't been accident prone before, these things will show up later in life, and the odds are you will have a lot of accidents.

This condition was intended to describe a negative outcome that was not connected with relationships or social exclusion. This method was used previously in Baumeister et al. (2002) and Twenge et al. (2001, 2002).

After hearing the prediction about their future lives, participants completed the PANAS (Watson et al., 1988) and the SSES (Heatherton \& Polivy, 1991). They were then presented with a list of 10 common proverbs and asked to "explain in your own words what you think it means." The proverbs included "People who live in glass houses shouldn't throw stones," "Don't cry over spilled milk," "Don't throw the baby out with the bathwater," and "A bird in hand is worth two in the bush." Participants were given 10 min to work on this task. We then counted the total number of words generated by each participant.

\section{Results and Discussion}

Would social exclusion cause people to be lethargic and not generate as many words in response to a definition task? We found that social exclusion did indeed lead to lethargy (see Table 3). Participants in the future alone condition generated significantly fewer words compared with the other two conditions, $F(2$, $40)=4.53, p<.02$. This effect was not due to simply hearing bad news. Participants in the future misfortune condition, who heard that their lives would involve frequent accidents, generated just as many words as participants in the future belonging condition. Planned contrasts showed that the future alone group wrote significantly fewer words than the other two groups (using Tukey's honestly significant difference [HSD], $p<.05$ ), but the future belonging and future misfortune groups were not significantly different from each other. Thus, at least on a task that required considerable meaningful thought, social exclusion resulted in a significant reduction in total output.

We attempted to code the interpretations for accuracy using two trained raters, but no significant differences were found. This might be dismissed as an uninterpretable null finding, possibly reflecting measurement difficulties. Alternatively, it may mean that the deconstructed state did not make people any less accurate in their ability to think-merely less inclined to do so.

There were no significant differences among the conditions in mood or state self-esteem (see Table 3). The null effect for mood replicated the results of Experiments 1 and 2, which also found no differences in mood between the accepted and rejected groups (except for the small difference on the one-item measure). Even with a different manipulation of social exclusion and a different mood measure, we found that social exclusion does not produce significant differences in mood.

The link between exclusion and lethargy was also not mediated by mood or by state self-esteem. To perform correlational analyses, we grouped the future belonging and future misfortune groups together to compare with the future alone group. The correlation between exclusion and words generated was still significant when controlled for negative mood, $r(40)=.44, p<.005$, and when controlled for positive mood, $r(40)=.40, p<.01$. In addition, neither mood scale was significantly correlated with number of words generated. The effect was also not mediated by state selfesteem; the correlation between exclusion and words was significant with state self-esteem controlled, $r(38)=.44, p<.005$, and the correlation between state self-esteem and words generated was not significant

Our control group in this study heard that they would be accident prone later in life, and this group did not display the lethargy seen in the future alone participants. Thus, not all types of negative feedback produced a passive response. One might ask if other types of negative feedback about one's future (e.g., failing in a career or having financial trouble) would also show null effects: Are these misfortunes just as "bad" as social exclusion, where

Table 3

The Effect of Social Exclusion on Word Generation, Mood, and State Self-Esteem, Experiment 3

\begin{tabular}{|c|c|c|c|c|c|c|c|}
\hline \multirow[b]{2}{*}{ Dependent variable } & \multicolumn{2}{|c|}{ Future belonging } & \multicolumn{2}{|c|}{ Misfortune } & \multicolumn{2}{|c|}{ Future alone } & \multirow[b]{2}{*}{$F(2,40)$} \\
\hline & $M$ & $S D$ & $M$ & $S D$ & $M$ & $S D$ & \\
\hline Words generated & 152.07 & 41.55 & 153.14 & 30.65 & 120.50 & 22.57 & $4.53^{*}$ \\
\hline Negative mood & 12.93 & 4.68 & 13.36 & 3.25 & 12.21 & 1.67 & 0.39 \\
\hline Positive mood & 30.07 & 6.28 & 30.36 & 4.53 & 26.86 & 8.99 & 1.14 \\
\hline State self-esteem & 58.93 & 5.23 & 53.92 & 11.77 & 55.21 & 8.98 & 1.21 \\
\hline
\end{tabular}

$* p<.05$. 
perhaps being accident prone is not? This question is almost impossible to answer: One would have to compare setbacks from different domains that have been equated on an objective scale of how "bad" they are. It is unlikely that such an objective scale exists.

\section{Experiment 4}

In Experiment 4, we examined lethargy in another way: by measuring participants' reaction times. The lethargic response would be a slower, sluggish reaction time. We returned to the group rejection manipulation used in Experiments 1 and 2, with participants hearing either that no one or everyone in a group had chosen them as a partner for further interaction. Participants then played a reaction-time game, ostensibly with another person but actually against the computer. They were told to click on a square when it turned red and a beep sounded. The program continued for 25 trials, but we did not necessarily expect the lethargic impairment to continue throughout the exercise. Novel tasks depend on controlled processes, including the self's executive function, whereas after a few trials the response can become familiar and well learned so that responses can be fairly automatic. Cognitive deconstruction is essentially a state of the self, and so it should mainly affect controlled processes while leaving the automatic ones untouched. The specific prediction was therefore that rejection would lead to slower responding on the early trials but not on the later trials.

\section{Method}

\section{Participants}

The participants were 100 undergraduates (49 men, 51 women) participating as part of a course requirement for introductory psychology. They were $74 \%$ White and $26 \%$ racial minority, and their average age was 18.6 years. Data on the aggressive behavior of these respondents were reported in Twenge et al. (2001) and Twenge and Campbell (2003).

\section{Materials and Procedure}

As in Experiments 1 and 2, participants arrived at the lab in single-sex groups of 4-6 people. They talked for $15 \mathrm{~min}$ and were then led to separate rooms, where they nominated the two people with whom they desired further interaction. Each participant was told either that everyone had picked him or her for the group task (accepted condition) or that no one had picked him or her (rejected condition).

Participants were then told that they would play the reaction time game with a nongroup member (someone who arrived too late to participate in the group discussion) because of the unusual vote. In actuality, the Macintosh computer was programmed to mimic a person's responses (a detailed description of this program is presented in Bushman \& Baumeister, 1998). Participants were told that they would have to press a button as fast as possible on each trial. A green square on the computer screen would first turn yellow, and then red; participants were told to click on the square as soon as it turned red. The program also produced an audio beep when the square turned red. The computer program recorded the reaction time of the participant on each trial.

\section{Results and Discussion}

Rejected participants $(M=495.61 \mathrm{~s})$ showed slower reaction time on the first trial, compared with accepted participants $(M=$
$326.92 \mathrm{~s}), F(1,98)=4.35, p<.04$. Thus, when the task was novel and unfamiliar, rejection led to slower reaction times. This fits the view that rejection causes lethargy that can interfere with controlled processing.

The second trial showed a trend in the same direction as the first turn, with rejected participants $(M=279.84)$ reacting slower than accepted participants $(M=244.92), F(1,98)=2.27, p=.13$. There were no significant differences on trials 3-25. The second trial reaction times were also faster overall (comparing the first and second turns), $t(200)=4.68, p<.001$, a trend that continued in the later trials. The faster reaction time on these trials supports the argument that automatic processes have begun to take over this function, leading to fewer differences between the experimental conditions. Thus, once the task was routine, rejected participants reacted just as fast as accepted participants. The implication is that rejection causes a lethargy in executive function that slows down controlled responses to an unfamiliar task but does not affect automatic responses to a familiar task.

\section{Experiment 5}

Experiments 1-3 found that social exclusion did not produce differences in self-reported mood across three different measures listing emotion words (although there was a small effect on a one-item mood rating in Experiment 1). All of these studies used explicit mood measures, in which participants were explicitly asked to rate their current mood on a variety of adjectives. It is possible that socially excluded people, in particular, are reluctant to admit to being in a negative mood. They may wish to preserve the illusion (to themselves and possibly to the experimenter) that they are unaffected by the social exclusion.

Experiment 5 was therefore designed to measure mood more implicitly. Participants first received the future prediction exclusion manipulation used in Experiment 3. In the crucial future alone condition, participants were told that they were likely to end up alone later in life. We simplified the design by including only one control group, who received no feedback at all. After the manipulation, participants sat in front of a computer programmed to display a line of $X \mathrm{~s}$ and then flash briefly. Participants were told that the computer would flash a word during this brief time (it actually flashed a blank screen) and that they should circle the word they thought they saw from a series of choices. There were 18 trials with four choices; each question had one emotion word and three neutral words as choices-for example, (a) TREAD; (b) BREAD; (c) SCARED; (d) FARED. The number of emotion words chosen served as the measure of emotional numbness.

Competing predictions could be made. If the lack of emotional response to rejection in previous work was an artifact of self-report methods, it remains plausible that rejection would cause substantial emotional distress. In this case, rejected participants would choose more negative emotion words and fewer positive emotion words. Alternatively, if rejection is emotionally neutral and unimpactful, then there would be no difference between conditions. Meanwhile, the cognitive deconstruction theory predicts that rejected participants would choose fewer emotion words (of either valence) than other participants, consistent with the view that deconstruction is essentially a move to shut down one's emotions. 


\section{Method}

\section{Participants}

Participants were 30 (10 men, 20 women) undergraduates who completed the experiment in return for course credit. They were $43 \%$ White and $57 \%$ racial minority, and their average age was 20.0 years.

\section{Procedure}

Participants completed the EPQ and were given accurate feedback about their extraversion score. They were then randomly assigned to either (a) hear the future alone prediction that they would be alone later in life (worded exactly the same as in Experiment 3), or (b) move directly to the next part of the experiment without hearing a future prediction. Participants then sat down at the computer and the experimenter explained the task. A Macintosh computer was used to present the stimulus material. We modified this technique from Hass, Katz, Rizzo, Bailey, and Moore (1992) and Koole, Smeets, von Knippenberg, and Dijksterhuis (1999). Participants were told that the computer would display a row of $X \mathrm{~s}$ and would then flash a word for a split second before returning to the screen with the row of $X \mathrm{~s}$ (in actuality, the computer showed a blank screen). On each of 18 trials, participants were asked to circle the word they thought they saw from among four choices with one emotion word and three other choices-for example, (a) RECANT; (b) PLEASANT; (c) REPLANT; (d) PRESENT. There were nine negative emotion words (down, scared, low, uneasy, upset, sad, nervous, anger, depressed) and nine positive emotion words (happy, content, pleasant, joyful, calm, good, pleased, glad, secure) drawn from Hass et al. (1992).

\section{Results and Discussion}

Future alone participants circled fewer emotion words overall (negative plus positive; $M=4.80$ ) compared with no-feedback participants $(M=6.93), F(1,28)=5.00, p<.04$. The results for negative words $(M$ for future alone $=1.67 ; M$ for no feedback $=2.47)$ and positive words $(M \mathrm{~s}=3.13$ and 4.47 , respectively) were in the same direction, with future alone participants circling fewer words, although those differences failed to reach significance.

These findings help rule out the view that the lack of emotional distress after rejection is simply an artifact of self-report measures. In this experiment, the task was implicit and more subtle. Endorsing emotion words in this procedure was presumably just a sign of accessibility. There was no sign that negative emotion (or positive emotion for that matter) was more accessible among people who anticipated a socially isolated future than among people who had received no feedback about their futures. On the contrary, the significant difference obtained in this study suggests that the prospect of social exclusion made all emotional responses less likely. These findings seem most consistent with the deconstruction hypothesis: Social exclusion is threatening, and people respond to it by attempting to shut down their emotions.

\section{Experiment 6}

Experiment 6 investigated another crucial feature of the deconstructed state: the attempt to escape from self-awareness. People shift to low levels of meaningful thought partially because they are reluctant to focus thoughtful attention on themselves; such attention would lead to distressing and painful reflections on one's flaws or inadequacies. Social exclusion raises the threatening possibility that something is wrong with the self (which causes others to reject you), and so people might defensively prefer not to dwell on those thoughts.

The procedure for measuring whether people avoid or seek self-awareness was adapted from Greenberg and Musham (1981). The room contained two chairs, one placed facing a mirror and the other with its back to the mirror and facing a blank wall. Participants were asked to sit down and wait for another experimenter. We then surreptitiously recorded which chair they chose: the one facing the mirror, with its increase in self-awareness, or the one facing away from the mirror, with its avoidance of self-awareness. Facing a mirror is a common technique for increasing selfawareness (Diener \& Wallbom, 1976), so the choice of the chair is a clear reflection of avoiding or embracing self-awareness. We predicted that socially excluded participants would be more likely to avoid self-awareness by choosing the chair facing away from the mirror

\section{Method}

\section{Participants}

Forty undergraduate students ( 26 men, 14 women) participated to fulfill introductory psychology course requirements. Data from 2 participants were discarded because 1 expressed suspicion and 1 did not follow directions (thus, there were originally 42 participants). The sample was $72.5 \%$ White and $27.5 \%$ racial minority, and the average age was 19.1 years.

\section{Procedure}

Participants were told that the study involved completing personality questionnaires and learning about one's personality, and they completed a demographic survey and the EPQ. Participants were randomly assigned to one of four social exclusion conditions: future alone, future belonging, future misfortune, or no feedback (similar to the method used in Experiment 3). They then completed the BMIS (Mayer \& Gaschke, 1988) and the SSES (Heatherton \& Polivy, 1991).

At this point, participants were told that this experiment was over. Because this experiment was so short (it usually took people only $15-20$ min to complete), participants were told that it was being combined with another "unrelated" experiment that would only take a few minutes. The second experiment, they were told, would be led by another experimenter who was having trouble getting people to sign up for his experiment because it was so short. This experiment would take place in a different lab across the hall. The experimenter did not present the participants with an explicit opportunity to decline participation in the second experiment. All participants had signed up for a 30-min session, and none refused to complete the second experiment.

The participant was then led to a separate laboratory in the same building to increase the believability of the cover story. The experimenter directed participants to a room that appeared to be in use: The door was ajar and the lights were on, but the experimenter was not there. The room contained two chairs placed back to back with a sign taped between them reading "Do Not Remove." Each chair was equidistant from the wall in front of it, and approximately equidistant from the door through which the participants entered the room (see Figure 1). One of the walls had a 36-in. $\times 48$-in. full-length mirror, and the other wall was blank. The positioning of the mirror was counterbalanced: half the time it was on the right side of the room and the other half the time it was on the left side.

When standing in the doorway, the participants could view the entire room. The experimenter acted surprised that the second experimenter was not waiting in the room, and commented to the participant that he probably stepped out to use the bathroom and should be back any minute. The 


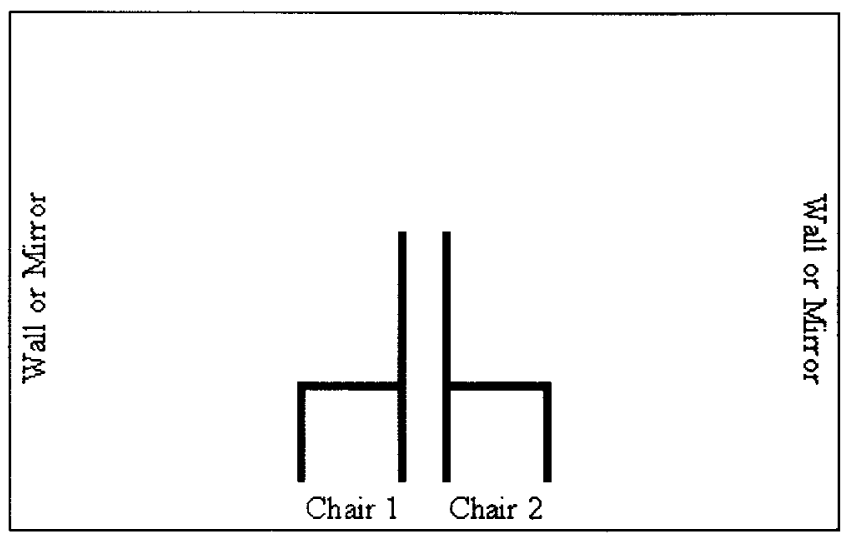

Figure 1. Diagram of experimental room for Experiment 6.

experimenter then said to the participant, "Why don't you have a seat, I'm sure [the experimenter] will be back in a minute." ${ }^{1}$ The participants' choice to sit either facing toward or away from the mirror was the main dependent variable of seeking or avoiding self-awareness.

The experimenter then left the room, ostensibly to search for the missing experimenter. She returned to the room saying that she didn't see him anywhere, but while the participant waited, he or she could fill out a questionnaire so they wouldn't get behind. The questionnaire assessed the strength of the participants' seating choice $(1=$ not at all strong to $9=$ extremely strong). Participants also reported their extraversion score, the prediction they had received for the future (if any), and how much they thought this prediction might describe their future $(1=$ not at all to $7=$ very much). These questions served as the manipulation check for the social exclusion manipulation. Finally, participants recorded what was on the wall in front of them (to confirm the experimenter's record) and wrote an open-ended explanation of their choice to sit either facing or away from the mirror. Participants were then carefully and thoroughly debriefed, thanked, and dismissed.

\section{Results}

\section{Manipulation Check}

Participants' memory for their predicted future and their belief that this prediction might describe their future served as a manipulation check for social exclusion. All participants correctly recalled their prediction for the future. Participants were also asked to rate their belief that this prediction would describe their future on a Likert scale $(1=$ not at all, $7=$ very much $)$. A one-way analysis of variance on this rating (comparing the three conditions who heard future predictions) showed a significant difference between conditions, $F(2,28)=10.99, p<.0001$. Tukey HSD post hocs revealed that people in the future belonging condition $(M=5.50, S D=1.27)$ were more likely to think that this prediction would describe their future than those in the future alone $(p<.0001)$ and future misfortune $(p<.001)$ conditions. People in the future alone $(M=2.50, S D=1.08)$ and future misfortune $(M=3.10, S D=2.02)$ conditions did not differ significantly in their belief that this prediction would describe their future.

\section{Avoiding Self-Awareness}

Would socially excluded people avoid self-awareness by choosing to sit facing a wall rather than risk facing their own reflection in a mirror? As Table 4 shows, those in the future alone condition were significantly more likely to avoid self-awareness by seating themselves facing away from the mirror. All but 1 future alone participant chose to face away from the mirror $(90 \%$ chose to avoid self-awareness by facing away). In contrast, participants in the other three conditions were evenly divided in their seating choices. The difference between the future alone condition and the three control conditions combined was significant, $\chi^{2}(1, N=$ $40)=5.76, p<.02$. Thus, the future alone participants consistently chose to avoid self-awareness by looking at a featureless blank wall rather than their own reflection in a mirror. Participants in the control conditions apparently chose their seats randomly.

The overall chi-square among the four conditions (future alone, future belonging, misfortune control, and no-feedback control) was also significant, $\chi^{2}(3, N=40)=9.31, p<.03$. In addition, the future alone group was significantly different from the misfortune control group, $\chi^{2}(1, N=20)=5.50, p<.05$, and from the no-feedback control group, $\chi^{2}(1, N=20)=7.50, p<.02$ (planned contrasts with Bonferroni corrections applied). Thus, the negative feedback had to be specific to relationships to cause avoidance of self-awareness; hearing that one would be physically hurt (future misfortune) did not increase the desire to face away from a mirror (in fact, $60 \%$ of these participants chose to face the mirror instead of the wall). This group was not much different from those who heard no prediction at all, $70 \%$ of whom chose to face the mirror (suggesting that facing a mirror rather than a wall is people's usual preference). Overall, the three control groups

\footnotetext{
${ }^{1}$ The experimenter was not blind to condition or to the hypotheses of this study. To reduce experimenter bias, the experimenter adhered to a strict script by precisely plotting her motions and verbal responses to create consistency across all conditions. By being consistent across all participants, the experimenter hoped to reduce any unconscious nonverbal or verbal behaviors that might confirm expectancies. The experimenter always stood in the same place before allowing the participant to enter the room with the mirror. Instead of leading the participant into the room, the experimenter always stood just beyond the threshold of the doorway while she commented that the second experimenter was absent. This motion blocked entrance to the room and left all participants standing in the doorway. This ensured consistency across conditions. It also prevented overeager participants from entering the room before they were instructed to do so and allowed them to view the set up of the room from behind the experimenter. Most importantly, this motion ensured that all participants entered the room from the same starting point and were never led into the room by the experimenter (which could potentially reveal experimenter expectancies). The experimenter always stepped aside to her right when finally allowing the participant to enter the room. Because the mirror was counterbalanced (it was sometimes on the right side of the room and sometimes on the left), the experimenter's stepping aside to the right should not create any particular response set in the participants. The experimenter always entered the room behind the participants once the participants had fully entered.

The experimenter also adhered to a strict verbal script. She never engaged in unnecessary conversation with participants while leading them to the second laboratory. She always gave the same verbal instructions to participants to sit down and wait for the experimenter. If the participant asked the experimenter where he or she should sit, the experimenter always responded, "Doesn't matter ... wherever you want." If participants lingered and did not sit down, she said, "You can take a seat now." After the participant chose a seat, the experimenter then told the participant that she would leave to find the other experimenter.
} 
Table 4

The Effect of Social Exclusion on Avoiding Self-Awareness, Experiment 6

\begin{tabular}{lccc}
\hline \multicolumn{1}{c}{ Experimental condition } & Chair facing mirror & Chair facing wall & \multicolumn{1}{c}{$\chi^{2}$} \\
\hline Future alone & $10 \%(n=1)$ & $90 \%(n=9)$ & \\
Control conditions combined & $53 \%(n=16)$ & $47 \%(n=14)$ & $\chi^{2}(1, N=40)=5.76^{*}$ \\
No-feedback control & $70 \%(n=7)$ & $30 \%(n=3)$ & $\chi^{2}(3, N=40)=9.31^{*}$ \\
Misfortune control & $60 \%(n=6)$ & $40 \%(n=4)$ & \\
Future belonging & $30 \%(n=3)$ & $70 \%(n=7)$ & \\
\hline
\end{tabular}

$* p<.05$.

were not significantly different from each other-future misfortune versus no feedback, $\chi^{2}(1, N=20)=0.22$; future misfortune versus future belonging, $\chi^{2}(1, N=20)=1.82$; no-feedback versus future belonging, $\chi^{2}(1, N=20)=3.20$. However, the future belonging group did not differ significantly from the future alone group, $\chi^{2}(1, N=20)=1.25$. This result was not expected. Perhaps hearing feedback about one's future relationships, whether good or bad, produces a tendency to avoid self-awareness. As the other contrasts demonstrate, negative feedback in and of itself does not produce the effect.

Despite a very clear behavioral preference to face the wall rather than to face the mirror ( $90 \%$ vs. $10 \%$ ), people who had been excluded were no more likely than others to self-report a stronger preference for their choice, $F(3,38)=2.32$ (rated on a 9-point Likert scale: future alone $M=4.40$; future belonging $M=3.00$; future misfortune $M=5.00$; no feedback $M=4.90$ ). Thus, future alone and control participants were equally certain about their seating choice. We also coded the participants' open-ended reasons for choosing the chair into three categories: no reason, proximity (which was counterbalanced and thus cannot account for the effect), and mention of wanting to look at or avoid the mirror. There were no significant differences among the conditions in their reasons for choosing one chair instead of another.

\section{Mood}

Mood was assessed using the BMIS (Mayer \& Gaschke, 1988), and results showed that there were no mood differences among conditions on the valence subscale, $F(3,38)=0.18, n s$, or the arousal subscale, $F(3,38)=1.20$, ns. Thus, the manipulation of social exclusion did not produce differences in mood. This is consistent with the previous experiments.

Also consistent with the previous experiments, mood did not mediate the effect. After controlling for both the valence and arousal subscales of the BMIS, social exclusion (future alone vs. the control groups) significantly predicted the self-awareness dependent measure, $r(37)=.38, p<.02$. In addition, neither mood valence nor arousal was significantly correlated with avoiding self-awareness after exclusion condition was controlled.

\section{State Self-Esteem}

The social exclusion manipulation also had no impact on participants' level of state self-esteem. Scores on the SSES did not differ significantly by condition for either the total state selfesteem score, $F(3,38)=0.04, n s$, or any of the three subscales (performance self-esteem, social self-esteem, or appearance self- esteem). Nevertheless, we tested for mediation. After controlling for state self-esteem scores, social exclusion (future alone vs. control groups) significantly predicted avoidance of selfawareness, $r(37)=-.41, p<.02$. Exclusion predicts the avoidance of self-awareness when state self-esteem is controlled, and thus state self-esteem does not mediate the relationship. However, state self-esteem was significantly correlated with self-awareness avoidance when social exclusion was controlled, $r(37)=-.38$, $p<.02$. This suggests that state self-esteem and social exclusion each had independent effects on the avoidance of self-awareness.

\section{General Discussion}

What happens inside the psyche of a person who is rejected by others? Intuition and theory had previously led us to expect that emotional distress would be a major, powerful result and that the behavioral consequences of social exclusion would be mediated by that distress. Yet, the data failed to support these theories and intuitions. Across multiple studies, our manipulations of social exclusion produced either weak or nonsignificant effects on emotional distress. Moreover, emotion consistently failed to show any sign of mediating the behavioral effects. It remains plausible that delayed emotional distress may be caused by rejection, but emotion certainly does not appear fast enough to affect behavior.

The present investigation was stimulated by the search for an alternative to emotional distress as an inner effect of social exclusion. We began by noting parallels to the research literature on suicide, which had also encountered many failures to confirm the intuitively and theoretically plausible prediction that the psyches of suicidal individuals would be brimming with intense, negative emotions. Although suicidal individuals were not found to be happy, cheerful souls, neither were they filled with anguish. The most common finding was that they showed emotional numbness, as if their emotional system had somehow shut down (see Baumeister, 1990, for a review). The responses of our laboratory participants had also indicated numbness, and the present findings confirmed this. In Experiment 5, for example, socially excluded participants chose fewer emotion words in an implicit measure of emotion disguised as a subliminal perception task. This is very similar to results with suicidal patients, who found it more difficult to access emotional memories and seemed the most comfortable with neutral stimuli (Geller \& Atkins, 1978; J. M. Williams \& Broadbent, 1986). This lack of emotional distress was also evident in Experiments 1-3 and 6, which showed null effects for exclusion on four different self-report measures; the only exception was a small difference on a one-item mood measure in Experiment 1. 
Several other labs working on rejection and ostracism have found significant mood effects (e.g., Buckley et al., in press; Snapp \& Leary, 2001; K. D. Williams, Cheung, \& Choi, 2000), and it seems prudent to discuss why our results differ. It is possible that the future alone manipulation (unique to us), which predicts an entire future of exclusion, produces stronger feelings of defense and deconstruction than the other types of manipulations. In addition, our group rejection procedure differs from that of Buckley et al. (in press). In those studies, participants never met their rejecting peers in person (instead, communication took place on paper or by speaking into a microphone without verbal feedback in return). Our participants met and talked with their peers in person before the rejection, which might have elicited a stronger defense response. Further research should attempt to determine if mood effects differ systematically on the basis of the specific rejection, exclusion, or ostracism manipulation used.

The main purpose of the present investigation was to test a series of predictions based on cognitive deconstruction. Deconstruction is a mental state found in suicidal individuals. It is assumed to reflect an attempt to avoid awareness of the self's deficiencies (as suggested by recent events-in this case, being rejected by others) along with the emotional distress that might accompany facing up to one's shortcomings and failures. The central reasoning was that social exclusion would thwart people's desire to be accepted by others, and consequently rejected people would enter the defensive state of cognitive deconstruction (in which the emotional distress and aversive self-awareness could be kept at bay). A series of predictions about the behavior of socially excluded individuals was confirmed. We now review the main findings.

\section{Findings Consistent With the Deconstructed State}

Time distortion is one sign of the deconstructed state. Time perception was altered among socially rejected participants in Experiment 1. They significantly overestimated the duration of experimentally timed intervals, in sharp contrast to the fairly accurate estimates in the control group. Overestimating the duration of intervals occurs when time is passing very slowly, such as when one is severely bored or life is generally empty.

The altered sense of time was also reflected in the lack of future orientation. On one measure, rejected participants in Experiment 1 were more likely to report that they were focused on the present and found it difficult to think about the future (although another measure, the ZTPI, did not show significant differences). The blockage of thoughts about the future, like the slowed passage of time, has been observed among suicidal people and is a defining feature of deconstruction. The meaningful construction of human life links different episodes across time, and the present often draws meaning from the future (e.g., when people explain their current activities in terms of goals or other anticipated future outcomes). Hence, much of the meaning of present events is eliminated when the future is blocked out of awareness.

The loss of meaning was confirmed with a different measure in Experiment 2. Socially rejected people did not disagree as strongly with the statement "Life is meaningless." These findings confirm and extend K. D. Williams's (2001) theory that ostracism threatens meaningful existence. Even when participants were randomly assigned to briefly experience rejection by a group of strangers, their views of life were affected. The possibility that life has no meaning became more probable. This fits the view that social exclusion produces a state incompatible with meaning-thus, a deconstructed state. If such a small brush with social rejection can make life seem more meaningless, long-term experiences of ostracism and exclusion are likely to produce deep-seated feelings of meaninglessness and despair.

Delay of gratification is an important key to success in life, but it requires a meaningful connection between the present (where sacrifices have to be made) in favor of the future (where goals are met and rewards anticipated). The deconstructed state is marked by disinhibited, impulsive behavior, which is presumed to reflect this lack of meaningful guidance of present behavior by future considerations. Experiment 1 measured delay of gratification by asking people how they would advise someone choosing between two jobs, one of which was better in the short run, whereas the other was better in the long run. Social exclusion led to a significant shift toward the job that was better in the short run (immediate gratification). Nearly all control participants favored the job that was better in the long run, but a sizeable minority of socially rejected participants voted in favor of the job with the short-term benefits. These findings converge with those reported by Twenge et al. (2002), in which excluded participants chose the short-term pleasures of magazines, candy bars, and video games over the longterm benefits of good health and doing well on an upcoming test.

Socially excluded people also displayed lethargy and passivity, other hallmark behaviors of the deconstructed state. In Experiment 3, excluded participants wrote fewer words when asked to define common proverbs, thus choosing to exert less effort at a cognitive task. Rejected participants in Experiment 4 demonstrated slowed reaction time on the first trial of a game, again showing lethargy in response to a novel task. Taken together, these studies show that social exclusion leads individuals to slow down, conserve energy, and generally behave in a lethargic and passive fashion. These results are consistent with those of K. D. Williams, Cheung, and Choi (2000), who found greater conformity among ostracized individuals. However, they are inconsistent with the results of K. D. Williams and Sommer (1997), who found that ostracized women worked harder on a subsequent group task. Future research should determine which rejection and ostracism situations lead to passivity and which do not.

We examined the role of mood in several studies. With the exception of the one-item measure in Experiment 1, none of the explicit measures of mood were affected by the social exclusion and rejection manipulations. In Experiment 5, participants completed an implicit mood measure, guessing which word they saw momentarily displayed on a computer screen. Excluded participants chose fewer emotion words, consistent with our prediction that exclusion leads to emotional numbness.

The ostensible purpose of the deconstructed state is to avoid emotion and self-awareness. We have already mentioned that the present findings confirmed the absence of emotion. Experiment 6 was designed to measure avoidance of self-awareness. Consistent with predictions, socially excluded participants showed a marked aversion for seats that faced a mirror (a self-focusing cue). Only one single participant in the rejection condition took the seat that faced the mirror. In contrast, control subjects seemed essentially indifferent as to whether they faced toward or away from the mirror, with about half the control participants choosing each seat. 
Social exclusion caused avoidance of mirrors, and this suggests that excluded people are averse to self-awareness.

\section{Concluding Remarks}

The present investigation has identified some intrapsychic consequences of social exclusion. Previous experiments found the emotional impact of exclusion to be muted, but the present findings indicate that there are in fact some discernible intrapsychic effects. These fit the pattern of a state of deconstruction, in which meaningful thought and self-awareness are avoided, attention is limited to the present, and action is slow and sparse. Deconstruction is a defensive state of mind, designed to ward off the negative consequences of rejection. This state may be mildly aversive, but it is preferred over the alternative of intense emotional distress and detailed ruminations about all one's misdeeds and faults that might have caused the rejection.

\section{References}

Baumeister, R. F. (1990). Suicide as escape from self. Psychological Review, 97, 90-113.

Baumeister, R. F. (1991). Escaping the self: Alcoholism, spirituality, masochism, and other flights from the burden of selfhood. New York: Basic Books.

Baumeister, R. F., \& Leary, M. R. (1995). The need to belong: Desire for interpersonal attachments as a fundamental human motivation. Psychological Bulletin, 117, 497-529.

Baumeister, R. F., Twenge, J. M., \& Nuss, C. K. (2002). Effects of social exclusion on cognitive processes: Anticipated aloneness reduces intelligent thought. Journal of Personality and Social Psychology, 83, 817827

Blewett, A. E. (1992). Abnormal subjective time experience in depression. British Journal of Psychiatry, 161, 195-200.

Brockopp, G. W., \& Lester, D. (1970). Time perception in suicidal and nonsuicidal individuals. Crisis Intervention, 2, 98-100.

Buckley, K. E., Winkel, R. E., \& Leary, M. R. (in press). Reactions to acceptance and rejection: Effects of level and sequence of relational evaluation. Journal of Experimental Social Psychology.

Bushman, B. J., \& Baumeister, R. F. (1998). Threatened egotism, narcissism, self esteem, and direct and displaced aggression: Does self-love or self-hate lead to violence? Journal of Personality and Social Psychology, 75, 219-229.

Csikszentmihalyi, M. (1990). Flow: The psychology of optimal experience. New York: Harper \& Row.

Diener, E., \& Wallbom, M. (1976). Effects of self-awareness on antinormative behavior. Journal of Research in Personality, 10, 107-111.

Durkheim, E. (1963). Suicide. New York: Free Press. (Original work published 1897)

Edwards, M. J., \& Holden, R. R. (2001). Coping, meaning in life, and suicidal manifestations: Examining gender differences. Journal of Clinical Psychology, 57, 1517-1534.

Eysenck, H. J., \& Eysenck, S. B. G. (1975). Manual of the Eysenck Personality Questionnaire. San Diego, CA: EdITS.

Geller, A. M., \& Atkins, A. (1978). Cognitive and personality factors in suicidal behavior. Journal of Consulting and Clinical Psychology, 46, $860-868$

Gerber, K. E., Nehemkis, A. M., Farberow, N. L., \& Williams, J. (1981). Indirect self-destructive behavior in chronic hemodialysis patients. Suicide and Life-Threatening Behavior, 11, 31-42.

Gjesme, T. (1979). Future time orientation as a function of achievement motives, ability, delay of gratification, and sex. Journal of Psychology, 101, 173-188.
Greaves, G. (1971). Temporal orientation in suicidals. Perceptual and Motor Skills, 33, 1020.

Greenberg, J., \& Musham, C. (1981). Avoiding and seeking self-focused attention. Journal of Research in Personality, 15, 191-200.

Hass, R. G., Katz, I., Rizzo, N., Bailey, J., \& Moore, L. (1992). When racial ambivalence evokes negative affect, using a disguised measure of mood. Personality and Social Psychology Bulletin, 18, 786-797.

Heatherton, T. F., \& Polivy, J. (1991). Development and validation of a scale for measuring state self-esteem. Journal of Personality and Social Psychology, 60, 895-910.

Hendin, H. (1982). Suicide in America. New York: Norton.

Henken, V. J. (1976). Banality reinvestigated: A computer-based content analysis of suicidal and forced-death documents. Suicide and LifeThreatening Behavior, 6, 36-43.

Kirkpatrick, L. A., Waugh, C. E., Valencia, A., \& Webster, G. D. (2002). The functional domain specificity of self-esteem and the differential prediction of aggression. Journal of Personality and Social Psychology, 82, 756-767.

Koole, S. L., Smeets, K., von Knippenberg, A., \& Dijksterhuis, A. (1999). The cessation of rumination through self-affirmation. Journal of Personality and Social Psychology, 77, 111-125.

Kuhlen, R. G., \& Monge, R. H. (1968). Correlates of estimated rate of time passage in the adult years. Journal of Gerontology, 23, 427-433.

Leary, M. R., Kowalski, R. M., Smith, L., \& Phillips, S. (2003). Teasing, rejection, and violence: Case studies of the school shootings. Aggressive Behavior, 29, 202-214.

Leary, M. R., Tambor, E. S., Terdal, S. K., \& Downs, D. L. (1995). Self-esteem as an interpersonal monitor: The sociometer hypothesis. Journal of Personality and Social Psychology, 68, 518-530.

Massong, S. R., Dickson, A. L., Ritzler, B. A., \& Layne, C. C. (1982). Assertion and defense mechanism preference. Journal of Counseling Psychology, 29, 591-596.

Mayer, J. D., \& Gaschke, Y. N. (1988). The experience and metaexperience of mood. Journal of Personality and Social Psychology, 55, $102-111$.

McGuire, M. T., \& Raleigh, M. J. (1986). Behavioral and physiological correlates of ostracism. Ethology and Sociobiology, 7, 187-200.

Mehrabian, A., \& Weinstein, L. (1985). Temperament characteristics and suicide attempters. Journal of Consulting and Clinical Psychology, 53, 544-546.

Melges, F. T., \& Weisz, A. E. (1971). The personal future and suicidal ideation. Journal of Nervous and Mental Disease, 153, 244-250.

Neuringer, C., \& Harris, R. M. (1974). The perception of the passage of time among death-involved hospital patients. Life-Threatening Behavior, 4, 240-254.

Rogers, J. R. (2001). Theoretical grounding: The "missing link" in suicide research. Journal of Counseling \& Development, 79, 16-25.

Sedikides, C., Campbell, W. K., Reeder, G. D., \& Elliot, A. J. (1999). The relationship closeness induction task. Representative Research in Social Psychology, 23, 1-4.

Snapp, C. M., \& Leary, M. R. (2001). Hurt feelings among new acquaintances: Moderating effects of interpersonal familiarity. Journal of Social and Personal Relationships, 18, 315-326.

Topol, P., \& Reznikoff, M. (1982). Perceived peer and family relationships, hopelessness, and locus of control as factors in adolescent suicide attempts. Suicide and Life-Threatening Behavior, 12, 141-150.

Trout, D. L. (1980). The role of social isolation in suicide. Suicide and Life-Threatening Behavior, 10, 10-23.

Twenge, J. M., Baumeister, R. F., Tice, D. M., \& Stucke, T. S. (2001). If you can't join them, beat them: Effects of social exclusion on aggressive behavior. Journal of Personality and Social Psychology, 81, 1058-1069.

Twenge, J. M., \& Campbell, W. K. (2003). "Isn't it fun to get the respect that we're going to deserve?": Narcissism, social rejection, and aggression. Personality and Social Psychology Bulletin, 29, 261-272. 
Twenge, J. M., Catanese, K. R., \& Baumeister, R. F. (2002). Social exclusion causes self-defeating behavior. Journal of Personality and Social Psychology, 83, 606-615.

Tysk, L. (1984). Time perception and affective disorders. Perceptual and Motor Skills, 58, 455-464.

Vallacher, R. R., \& Wegner, D. M. (1985). A theory of action identification. Hillsdale, NJ: Erlbaum.

Vallacher, R. R., \& Wegner, D. M. (1987). What do people think they're doing: Action identification and human behavior. Psychological Review, 94, 3-15.

Watson, D., Clark, L. A., \& Tellegen, A. (1988). Development and validation of brief measures of positive and negative affect: The PANAS scales. Journal of Personality and Social Psychology, 54, 1063-1070.

Wegner, D. M., \& Giulano, T. (1980). Arousal-induced attention to self. Journal of Personality and Social Psychology, 38, 719-726.

Weiss, J. M. (1957). The gamble with death in attempted suicide. Psychiatry, 20, 17-25.

Williams, J. M., \& Broadbent, K. (1986). Autobiographical memory in suicide attempters. Journal of Abnormal Psychology, 95, 144-149.

Williams, K. D. (2001). Ostracism: The power of silence. New York: Guilford Press.

Williams, K. D., Bernieri, F., Faulkner, S., Grahe, J., \& Gada-Jain, N. (2000). The Scarlet Letter study: Five days of social ostracism. Journal of Personal and Interpersonal Loss, 5, 19-63.
Williams, K. D., Cheung, C. K. T., \& Choi, W. (2000). CyberOstracism: Effects of being ignored over the Internet. Journal of Personality and Social Psychology, 79, 748-762.

Williams, K. D., Govan, C. L., Croker, V., Tynan, D., Cruickshank, M., \& Lam, A. (2002). Investigations into differences between social- and cyber-ostracism. Group Dynamics: Theory, Research, and Practice, 6, $65-77$.

Williams, K. D., Shore, W. J., \& Grahe, J. E. (1998). The silent treatment: Perceptions of its behaviors and associated feelings. Group Processes and Intergroup Relations, 1, 117-141.

Williams, K. D., \& Sommer, K. L. (1997). Social ostracism by one's coworkers: Does rejection lead to loafing or compensation? Personality and Social Psychology Bulletin, 23, 693-706.

Wyrick, R. A., \& Wyrick, L. C. (1977). Time experience during depression. Archives of General Psychiatry, 34, 1441-1443.

Yufit, R. I., \& Benzies, B. (1973). Assessing suicidal potential by time perspective. Life-Threatening Behavior, 3, 270-282.

Zimbardo, P. G., \& Boyd, J. N. (1999). Putting time in perspective: A valid, reliable individual-differences metric. Journal of Personality and Social Psychology, 77, 1271-1288.

Received November 18, 2002 Revision received April 14, 2003 Accepted April 23, 2003

\section{New Editor Appointed for Contemporary Psychology: APA Review of Books, 2005-2010}

The Publications and Communications Board of the American Psychological Association announces the appointment of Danny Wedding (Missouri Institute of Mental Health) as editor of Contemporary Psychology: APA Review of Books, for a 6-year term beginning in 2005. The current editor, Robert J. Sternberg (Yale University), will continue as editor through 2004.

All reviews are written by invitation only, and neither the current editor nor the incoming editor receives books directly from publishers for consideration. Publishers should continue to send three copies of books for review consideration, along with any notices of publication, to PsycINFO Services Department, APA, Attn: Contemporary Psychology: APA Review of Books Processing, P.O. Box 91600, Washington, DC 20090-1600 or (for UPS shipments) 750 First Street, NE, Washington, DC 20002-4242. 